\title{
Owner Motivations in the UK Speciality Food Sector
}

\author{
by \\ Andrew D. Bugg \\ ESRC Centre for Competition Policy \& School of Economics, \\ University of East Anglia, UK \\ CCP Working Paper 07-4
}

\begin{abstract}
This paper investigates empirically whether owner motivations are consistent with neoclassical models of profit maximisation. Contrary to the neoclassical model, in some markets owners gain private benefits from supplying products with certain characteristics. To consider this issue, a full theoretical model that allows owners to consider not only profit, but also utility, in their choices of price, product quality, and the use of an owner-specific production method was developed. Information was gathered on owner motivations from the UK speciality food sector to test the propositions of the theoretical model. Evidence of systematic utility maximisation is found and utility maximising owners set higher profit maximising prices and produce a higher quality product. These findings have implications for the UK speciality food sector.
\end{abstract}

March 2007

JEL classification: C1; C3; L1; L2; L7; Q1.

Key Words: Speciality food; objective function heterogeneity; factor analysis; seemingly unrelated regressions.

\section{Acknowledgements:}

I would like to thank Bruce Lyons and Peter Moffatt for guidance; and Stephen Davies, Morten Hviid, Alistair Munro, Matt Olczak, Chris Wilson and Luke Garrod for additional comments. Also thanks go to participants of the $2^{\text {nd }} \mathrm{CCP}$ $\mathrm{PhD}$ Workshop, July $29^{\text {th }} 2006$ and of the EARIE annual conference, University of Amsterdam, August 2006, for their comments. Support from the Economic and Social Research Council is gratefully acknowledged.

Contact Details: Andrew Bugg, ESRC Centre for Competition Policy, University of East Anglia, Norwich, NR4 7TJ, UK, a.bugg@uea.ac.uk 


\section{Introduction}

In this paper we investigate empirically whether owner motivations are consistent with the neoclassical model of profit maximisation. Contrary to the neoclassical model, if owners gain private benefits from supplying products with certain characteristics, it may be that too many characteristics are supplied to the market. The existence of such owner incentives could be important when considering competition policy in such sectors.

We focus our attention on the United Kingdom (UK) speciality cheese sector within the UK food industry. There is much evidence within the literature to suggest that owner motivations in this sector are not simply influenced by the demand side (i.e. ability to generate revenues), as would be assumed under the assumptions of the neoclassical model of profit maximisation, but are to some extent influenced by the supply side (i.e. pleasure from production).

To provide an insight into the UK speciality cheese sector, Kupeic and Revell (1998) provide a useful summary. They state that the sector comprises of both artisanal and speciality producers. Artisanal producers are non-industrial, such as agriculturally based producers, whereas speciality producers extend to include larger industrial producers, such as creameries. They go on to state that speciality cheese in 1996 represented one quarter of the UK cheese markets valued at $£ 1.6$ billion. The speciality cheese sector is interesting because it contains a diverse spectrum of producers where it is possible to observe a range of owner motivations.

To the best of our knowledge there is very little work that has investigated the supply side of the speciality cheese sector in the UK and more generally the UK speciality food sector. A recent study in the US by Scott Morton and Podolny (2002) concluded with evidence that owners of wine-producing firms in California maximise utility beyond pure profits. They test a non-formalised model of utility maximisation and detect utility maximising wine producers 
setting higher prices and producing higher quality wines compared to profit maximising owners.

Further studies motivate this paper. Tregear (2003a) suggests that in sectors such as crafts, which include cheese makers, lifestyle motivations were important for producers as well as more commercial aims and objectives, and it is the method of production that is crucial in separating different types of producers. Furthermore, Tregear (2003b) when classifying typical food products in the UK, suggests producer motivations as a contributor to the nature of each class defined. In this case, producer motivations are seen to be influential to the evolutionary paths of typical products in the UK. Christy and Norris (1999) in their study of the UK speciality cheese sector suggest that owners may well be prepared to suffer higher costs in compensation for their chosen methods of production and ingredients, which may not be of the best practice kind.

De Roost and Menghi (2000) in their study of Italian Parmigiano Reggiano cheese producers noted that privately-owned firms as opposed to larger industrial producers were found to receive lower returns from their efforts because they "... produced out of the passion for the product..." (p.445). They also suggest that industrial producers do not feel the same way about their product and instead profit maximising motivations are more important.

Outside academic literature, DTZ Pieda Consulting (1999) suggest that products from the UK speciality food sector were often differentiated in several ways such as being hand crafted, packaging, marketing and distribution channels. They also reported that central to the definition of speciality food is an important 'product focus', contrary to a 'company focus'. Again, this provides motivation for the paper as there may be producers within the UK speciality cheese sector that produce cheese to maximise utility beyond pure profits.

Given our motivation for this paper, we seek to investigate the latter by deriving a full theoretical model that allows owners to consider not only profit, but also utility, in their choices of price, product quality and the use of owner-specific production methods. The three propositions of this model are then tested 
empirically. To do this we collected information on owner motivation from the UK speciality cheese sector. Using this information, we then used a data reduction technique to create two new variables, assigned to each owner. The first new variable weights owners based on the extent to which they demonstrated having utility maximising motivations. The second weights owners based on their degree of profit maximising motivation. It was then possible to test the theoretical propositions simultaneously.

The remainder of this paper is structured as follows. Section 2 presents the theoretical model. In Section 3 we present the survey data and discuss the survey methodology. Section 4 presents the empirical modelling and the estimation results. Section 5 summarises the paper.

\section{Theoretical Model}

In this section we introduce the theoretical model. Owner motivations within the UK speciality cheese sector are interesting for two reasons. First, owners dominate all or much of the firm activity given that many are active members of the labour force producing cheese. ${ }^{1}$ Second, as many speciality cheese producers are family-owned enterprises, their motivation may differ compared to nonfamily-owned enterprises. As a result decision making on issues such as ingredients and the production methods used to achieve the desired cheese characteristics are taken at this level. It is fair to say that owner motivations can be assumed to reflect the decision making element of the enterprise and therefore its policy. In cases where there are multiple owners, a major shareholder was asked to represent the decision making element of the enterprise.

Speciality food products are differentiated where sellers compete horizontally by appealing to the heterogeneous tastes of consumers. In this type of market products are differentiated in many ways such as links to territory, traditional

\footnotetext{
${ }^{1}$ This is believed to be especially true for family enterprises where generally there is no board of directors to steer the business through some form of collective action.

${ }^{2}$ Product differentiation in this sector may be more complex. Marketing and distribution (local, regional, national and international markets for example) are other ways that differentiate cheeses. See DTZ Pieda Consulting (1999).
} 
methods of production, being hand crafted, use of quality raw materials and so on. ${ }^{2}$ Enterprises compete in Bertrand competition. By defining $q, p$ and $s$ as product demand, product price and product quality respectively, each seller faces a strictly downward sloping demand curve $q(p, s, \bar{p}, \bar{s})$ where $q_{p}<0, q_{s}>0$ and $q_{p s}>0 . \bar{p}$ and $\bar{s}$ are vectors of price and quality chosen by other owners. The utility maximisation problem for the owner is presented in (1) below. Here, an owner maximises a utility function with respect to $p, s$, and $t$ where $t$ is the use of a traditional production technology $t \in[0, \infty)$. The maximisation problem is:

$$
\max _{\mathrm{p}, \mathrm{s}, \mathrm{t}} u(p, s, t) \text { where } u(p, s, t)=q(p, s, \bar{p}, \bar{s}) p-C(q(p, s, \bar{p}, \bar{s}), s, t)+\beta \lambda(s, t)
$$

The first term on the right hand side is the total revenue that the owner obtains from selling $q$ units at price $p$. The use of a traditional production technology, $t$, is not included in the total revenue function as it has no value to consumers. The reason for this assumption is based on the fact that this traditional production technology is assumed not to be better that of other producers, but potentially costs more. A classic example would be the use of a traditional piece of equipment that adds authenticity purely for the pleasure of the producer but is more costly and no better than the best practice production method. Furthermore, the production method may not be verifiable to the consumer. ${ }^{3}$ If production methods were both verifiable for the consumer and demand enhancing, it would have the same effect in our model as enhancing quality $(s)$. In the absence of such information, it does not affect the demand curve. We assume the secondorder cross partial for quality with respect to the use of a traditional production method, $u_{s t}$, is equal to zero (see appendix A).

The second term in (1) represents total costs. Total cost is a function of $q, s$ and $t$. The total cost function is assumed to be convex and increasing in both $q$ and $s$ with standard assumptions: $C_{q}>0, C_{q q}>0 ; C_{s}>0, C_{s s}>0$ and $C_{q s}>0$. We

\footnotetext{
${ }^{3}$ Best practice production methods refer to techniques that use the latest technology in production.
} 
make further assumptions regarding the application of $t$. The first order, second order and second order cross partials with respect to $t$ and $q$ are: $C_{t}>0$ except $C_{t}(q, s, 0)=0, C_{t t}>0$ and $C_{q t} \geq 0$. The implication of this assumption for profit maximising owners is that they would set $t=0$ as doing so increases marginal costs with no gains to overall total revenue. Also $C_{s t} \approx 0$.

The last term in (1) measures the benefits, $\lambda$, that owners obtain from producing at some level of $s$ and employing $t$. The parameter $\beta$ is the importance an owner puts on non-profit utility. We refer to the higher $\beta$ owners as utility maximising. For profit maximising owners this equals zero $(\beta=0)$. Here, we assume that $\lambda$ is concave and increasing in $s$ and $t$ such that the first and second order differentials with respect to $s$ and $t$ are: $\lambda_{s}>0, \lambda_{s s}<0, \lambda_{t}>0$ and $\lambda_{t t}<0$. We further assume that quality is more important that the production method, therefore $\lambda_{s t} \approx 0$. More formally, we assume $\lambda_{s}$ is sufficiently greater than $\lambda_{t}$. This allows us to derive three testable propositions. Full proofs are in appendix A. These proofs take full account of the interactions between $t, s$ and $p$. In what follows, we sketch the intuition.

Proposition $1 \partial t / \partial \beta>0$. Utility maximising owners $(\beta>0)$ are more likely to use more owner-specific production methods.

Intuition Rearranging the first order condition for $t$, utility maximising owners will choose to use owner-specific production methods to the point where:

$$
C_{t}=\beta \lambda_{t}
$$

For profit motivated owners $\lambda_{t}=0$, so they set $t=0$. For utility maximising owners with $\beta>0$, since $\lambda_{t}>0$ then $t>0$ will be used in search of extra utility by using owner-specific production methods, face higher costs. 
Proposition $2 \partial s / \partial \beta>0$. If quality is more important than the use of an ownerspecific production method, such that $\lambda_{s}$ is sufficiently greater than $\lambda_{t}$, then utility maximising owners will produce a higher quality product.

Intuition Rearranging the first order condition for $s$, utility maximising owners will produce a higher quality product and as a result face higher levels of marginal cost of quality.

$$
C_{s}=q_{s}\left(p-C_{q}\right)+\beta \lambda_{s}
$$

Defining $s^{U M}$ and $s^{P M}$ as the quality level set by utility maximising owners and profit maximising owners respectively, if $\beta>0$ and since $\lambda_{s}>0$, then $s^{U M}>s^{P M}$. As a result, $C_{q}^{U M}>C_{q}^{P M}$. Intuitively, utility maximising owners search for extra utility through supplying extra quality to the market. However, they face higher marginal costs which limits this effect.

Proposition $3 \partial p / \partial \beta>0$. Utility maximising owners (high $\beta$ ) set higher prices compared to their profit maximising counterparts (low $\beta$ ).

Intuition This can be shown from the first order condition with respect to $p$. Utility maximising does not change the standard pricing condition in (4) below.

$$
\frac{p^{*}-C_{q}}{p^{*}}=\frac{1}{|\varepsilon|} \geq 0
$$

As the marginal cost increases, due to higher $s$ and $t$, the price set by a utility maximising owner, $p^{*}$, must rise. 


\section{Survey Data}

In this section we describe the survey methodology and the data. A questionnaire was designed to collect information on owner motivations within the UK speciality cheese sector, along with some descriptive information. Two producers agreed to pilot the questionnaire and report any comments using an appraisal form that accompanied the questionnaire. The pilot highlighted several improvements to the question ordering and general layout of the questionnaire.

After piloting it was appropriate to enlist support for and raise awareness of the survey amongst owners. A total of 257 owners were contacted by telephone and were asked if they would take part in the survey. Their name, telephone number and addresses were collected via on-line database searches. Only 52 declined to take part. This process was useful for three reasons. First, it gave owners an opportunity to decline and thus saved costs on postage and other materials; second, it helped to amend the list of owners entered on the database, again to reduce costs of wastage; and third, it helped the owner recall the telephone conversation upon receipt of the questionnaire.

The final questionnaire was sent to 205 speciality cheese producers in the UK. Each questionnaire was accompanied by a covering letter. Furthermore, a help sheet also accompanied the questionnaire and covering letter to provide assistance to any questions the owners may have had in supplying their information.

Owners were given eight weeks to reply. As suggested by Dillman (1980), two weeks after mailing the questionnaire, a reminder letter was sent to all nonrespondents. After another two weeks another reminder letter was sent 
accompanied by a replacement questionnaire. The survey achieved a $43 \%$ response rate. ${ }^{4}$

As a brief descriptive insight of those that returned the questionnaire, 92\% of businesses were family-owned, had an average operating age of 23 years, owned production equipment with a mean value of between $£ 16,000$ and $£ 63,999$, and $34 \%$ of respondents concentrated solely on the production of cheese. In terms of distribution, $52 \%$ sold directly to consumers, $8 \%$ sold directly to local shops, and $36 \%$ supplied to wholesalers that sell locally and nationally.

Owners were asked ten questions to establish the extent, if any, of their utility maximising behaviour. Table 1 introduces the survey variables. There is much evidence to suggest that utility maximising behaviour is present within the sector. $50 \%$ of respondents stated that they would be willing to lose money to improve the quality of their cheese. Furthermore, $60 \%$ of owners were either 'somewhat unlikely' or 'very unlikely' to sell if they were offered a fair value in cash with the caveat that it would earn more in a bank or building society account. 14\% stated that profits were a small part of family income or did not contribute to family income at all. $40 \%$ stated that the lifestyle of owning a cheese-making business was important.

Table 2 shows, by examining pair-wise correlations between survey variables, that owners are significantly systematic in their utility maximising behaviour. Owners that have no rate of return in mind on their investments are significantly willing to lose money for quality. Owners that enjoy producing cheese are motivated significantly by the lifestyle associated with owning a cheese-making business. In addition, these owners that enjoy producing cheese have more nonfinancial motivations and believe family ownership is not important in the future. The latter relationship suggests that the idea of family ownership not being important in the future is a purely non-altruistic attitude consistent with utility

\footnotetext{
${ }^{4}$ One weakness of this overall approach was the potential impact of firm size on non-response bias. However, it is not possible to estimate any non-response bias in this case due to the difficulty in distinguishing concrete and identifiable characteristics of all producers prior to the time of mailing the survey.
} 


\begin{tabular}{|c|c|c|c|c|c|c|}
\hline Survey Question & Upper Limit & Obs. & Mean & Std. dev. & Min & Max \\
\hline Willing to lose money for quality & $>£ 1000$ & 88 & 2.557 & 1.721 & 1 & 5 \\
\hline Unlikely to sell for fair value & V. Unlikely & 88 & 3.648 & 1.423 & 1 & 5 \\
\hline Little additional investment if more resources became available & None & 88 & 2.545 & 1.113 & 1 & 4 \\
\hline Profits cover costs only & Max Profit & 88 & 2.352 & 0.568 & 1 & 3 \\
\hline No specific rate of return in mind & No & 88 & 1.795 & 0.406 & 1 & 2 \\
\hline Continuing family ownership unimportant & No & 89 & 2.072 & 1.101 & 1 & 4 \\
\hline Profits a small part of family income & Insignificant & 88 & 2.102 & 1.213 & 1 & 5 \\
\hline Amount of socialising with other producers & $<50 \%$ & 89 & 1.910 & 0.949 & 1 & 5 \\
\hline Entertain other producers & Never & 89 & 3.629 & 0.628 & 1 & 4 \\
\hline Entertain consumers & Never & 89 & 3.123 & 1.166 & 1 & 12 \\
\hline Non-financial motivation - lifestyle & Yes & 88 & 0.398 & 0.492 & 0 & 1 \\
\hline Non-financial motivation - Enjoyment & Yes & 88 & 0.659 & 0.477 & 0 & 1 \\
\hline Non-financial motivation - Other & Yes & 88 & 0.398 & 0.492 & 0 & 1 \\
\hline Sum of motivations & 6 & 87 & 2.652 & 1.152 & 1 & 5 \\
\hline Percentage of cheeses named after the family & $100 \%$ & 89 & 3.809 & 2.251 & 1 & 6 \\
\hline Age of enterprise & - & 89 & 22.970 & 25.805 & 0.41 & 164 \\
\hline
\end{tabular}

Table 1 - Descriptive Results for Survey Questions; Owner Motivations 


\begin{tabular}{|c|c|c|c|c|c|c|c|c|c|c|c|c|c|c|c|c|}
\hline & $\mathrm{A}$ & B & $\mathrm{C}$ & $\mathrm{D}$ & $E$ & $\mathrm{~F}$ & G & $\mathrm{H}$ & I & $\mathrm{J}$ & $\mathrm{K}$ & $\mathrm{L}$ & $\mathrm{M}$ & $\mathrm{N}$ & $\mathrm{O}$ & $P$ \\
\hline A & 1 & & & & & & & & & & & & & & & \\
\hline B & -0.0078 & 1 & & & & & & & & & & & & & & \\
\hline $\mathrm{C}$ & $0.1041^{*}$ & 0.0619 & 1 & & & & & & & & & & & & & \\
\hline $\mathrm{D}$ & $0.1520^{*}$ & $0.2592^{*}$ & $0.1294 *$ & 1 & & & & & & & & & & & & \\
\hline E & -0.0646 & $-0.0941 *$ & -0.0407 & $0.1020^{*}$ & 1 & & & & & & & & & & & \\
\hline $\mathrm{F}$ & $-0.0958^{*}$ & $-0.1369^{*}$ & 0.0748 & $-0.1563^{*}$ & $-0.1341^{*}$ & 1 & & & & & & & & & & \\
\hline G & -0.0402 & $-0.1665^{*}$ & $0.1080^{*}$ & $0.3459^{*}$ & $0.2564^{*}$ & $-0.1906^{*}$ & 1 & & & & & & & & & \\
\hline $\mathrm{H}$ & -0.0247 & $0.1522^{*}$ & $0.2212^{*}$ & $0.2176^{*}$ & $0.1197^{*}$ & -0.0785 & -0.0674 & 1 & & & & & & & & \\
\hline I & -0.0428 & $0.0601 *$ & $0.1333^{*}$ & $0.3163^{*}$ & $-0.1696^{*}$ & $-0.3537 *$ & 0.0634 & $0.3066^{*}$ & 1 & & & & & & & \\
\hline J & $-0.1015^{*}$ & $0.2489^{*}$ & 0.0602 & $0.3754^{*}$ & $0.1253^{*}$ & -0.0287 & $0.1344 *$ & 0.0379 & $-0.1682 *$ & 1 & & & & & & \\
\hline K & $0.3706^{*}$ & $0.1521^{*}$ & -0.0362 & $0.7494 *$ & -0.0044 & $-0.0975^{*}$ & $0.2621^{*}$ & $0.1553^{*}$ & $0.3016^{*}$ & 0.0368 & 1 & & & & & \\
\hline $\mathrm{L}$ & $0.2214 *$ & $0.0893 *$ & $0.3419^{*}$ & $0.5278^{*}$ & $0.2041^{*}$ & 0.0526 & $0.0966 *$ & $0.1837 *$ & 0.0903 & 0.0457 & $0.1837 *$ & 1 & & & & \\
\hline M & $0.1097^{*}$ & $-0.2494 *$ & 0.0819 & $0.1014^{*}$ & $0.1831^{*}$ & $0.1389^{*}$ & $0.1057^{*}$ & $-0.2195^{*}$ & $-0.1079 *$ & 0.0465 & $-0.2195^{*}$ & $0.2800^{*}$ & 1 & & & \\
\hline $\mathrm{N}$ & -0.0491 & $-0.1304 *$ & $-0.2010^{*}$ & 0.0162 & $0.2531^{*}$ & $-0.1778^{*}$ & $0.1036^{*}$ & $-0.1305^{*}$ & $-0.1126^{*}$ & $0.2029 *$ & $-0.1305^{*}$ & $-0.1812 *$ & $-0.0992 *$ & 1 & & \\
\hline o & 0.0846 & -0.0078 & 0.1041 & $0.1520^{*}$ & -0.0646 & -0.0958 & -0.0402 & -0.0247 & -0.0043 & -0.1015 & $0.3706^{*}$ & $0.2214^{*}$ & $0.1097^{*}$ & -0.0491 & 1 & \\
\hline $\mathrm{P}$ & $0.7144 *$ & -0.0078 & 0.0839 & $0.2416 *$ & $-0.1777 *$ & -0.0888 & $0.1380^{*}$ & $-0.2184 *$ & 0.0681 & 0.0022 & $0.4247 *$ & 0.0790 & 0.1062 & -0.0137 & $0.1380^{* *}$ & 1 \\
\hline
\end{tabular}

Notes: *10\% significance or better. Key to Table: (A) Entertaining consumers (B) Unlikely to sell for fair value (C) Willing to lose money for quality (D) Sum of non-financial motivations (E) Percentage of cheeses named after family (F) Little additional investment if more resources became available (G) No rate of return in mind (H) Age of enterprise (I) Amount of socialising with other producers (J) Motivated by the enjoyment of producing cheese (K) Motivated by the lifestyle of producing cheese (L) Other non-financial motivations (M) Continuing family ownership unimportant (N) Profits are a small part of total family income (O) Cover costs (P) Entertain other producers.

Table 2 - Pair-wise Correlations; Survey Variables 
The three choice variables that represent $p, s$, and $t$ within the theoretical framework are wholesale prices, the percentage of milk produced by the owner's own herd or flock, and handmade methods respectively. ${ }^{5}$ The availability of no exogenous measures of cheese quality posed a problem for this analysis. Ideally, an exogenous measure of cheese quality would have been preferred as used by Scott Morton \& Podolny (2002). Therefore, information on the percentage of milk produced by the owner's own herd or flock was collected to supply a wellknown endogenous measure of quality within the sector, scrutinised by outside experts. The justification for this measure rests with the fact that owners that buy in milk that needs to travel and, as such, requires pasteurisation before being used for their cheese production, generally produce cheeses that lack the flavours of cheese made with un-pasteurised milk. Milk that has to travel less between its source and creamery retains flavours otherwise lost during transport. For example, Freeman (2003) states that the Lincolnshire Wolds provides grass for grazing that: “...yields milk with an enviable range of flavours.” (p.225). We use this measure of quality for the empirical testing of the theoretical model.

To have some measure of owner specific production methods, we asked owners to state if their cheese was handmade. $88 \%$ of owners that returned the questionnaire specified that their cheese was hand made with the remainder of the sample using 'best practice' methods of production.

\footnotetext{
${ }^{5}$ Wholesale prices were available across nearly all respondents. One weakness of using wholesale prices is that they may not account for possible mark up at the point of sale. Therefore, our later price estimations can be viewed strictly as approximations.
} 


\section{Empirical Models and Estimation Results}

In this section we test empirically the three propositions of our theoretical model using the data collected from the UK speciality cheese sector. There are two steps to our analysis. First, we consolidate the information on owner motivations provided by the survey questions. To do this we use a well-known data reduction technique, principal factor analysis (PFA), to create two variables that are correlated with the set of survey motivational variables. The first new variable scores owners' degree of utility maximising behaviour and the other scores owners' degree of profit maximising behaviour. In other words, each owner has two scores, one utility orientated, the other profit orientated, thus allowing for a range of motivation types to be accommodated in the empirical analysis. The second step is to test the propositions of the model. We estimate a reduced form, seemingly unrelated regression model of price, quality and the use of a traditional production technology as the exogenous choice variables of owners on the two new variables. We also test for correlation of errors within the system of equations to examine if owners' choices of price, quality and production technology are linked.

\subsubsection{Principal Factor Analysis}

In order to empirically test the three propositions of this paper it was necessary and desirable to reduce the number of variables that sought to investigate the same underlying behaviour (utility maximising behaviour) on the part of owners, into a smaller set of variables. PFA, which estimates factors to reduce the dimensionality of the set of motivational variables to just a few factors, was conducted in STATA. ${ }^{6}$ This technique extracts factors which explain the variance within the set of motivational variables. The components were then rotated using a varimax rotation. This is an orthogonal rotation procedure which aims to maximise the variance of the squared elements of the columns of the factor matrix, enhancing the interpretation of the factor loadings on the

\footnotetext{
${ }^{6}$ In STATA the factor command was used with its default setting $p f$ to conduct principal factor analysis.
} 
motivational variables. We use only two factors, generated by PFA, which contribute the most to the variance of the set of motivational variables.

Table 3 presents the factor loadings on each of the survey motivational variables. The first factor summarises the degree to which owners have a utility maximising attitude. This factor has the highest contribution to variance of all the factors extracted by the PFA. We call this factor the pleasure factor. It weights all the motivational variables positively with the exception of investing a little if more resources became available, continuing family ownership being unimportant and profits being a small part of family income. It is therefore recognising owners within the data that have non-financial benefits from owning a speciality cheesemaking enterprise.

The second factor is called the business factor. This is the second factor extracted by the PFA. We use this factor because it has the second highest contribution to variance with all the motivational variables. Ten out of the sixteen motivational variables are weighted negatively by this factor. This indicates that it is clearly picking up owners within the sample that have financial motivations for owning a cheese-making enterprise. Of the variables that this factor weights positively, two are weighted greater than the pleasure weighting for the same variable and three are weighted to a lesser extent. In other words, the pleasure factor is picking up owners that have non-financial motivations over and above the business factor in these cases. 


\begin{tabular}{lcc}
\hline Motivational Variable & Pleasure & Business \\
\hline Willing to lose money for quality & 0.039 & -0.068 \\
Unlikely to sell for fair value & 0.229 & 0.050 \\
Percentage of cheeses named after family & 0.060 & 0.140 \\
Little additional investment if more resources became available & -0.117 & 0.069 \\
Amount of socialising with other cheese producers & 0.114 & -0.008 \\
Length of time have owned the enterprise & 0.192 & 0.166 \\
No specific rate of return in mind & 0.329 & 0.045 \\
Motivated by enjoyment of producing cheese & 0.214 & 0.086 \\
Continuing family ownership unimportant & 0.040 & -0.101 \\
Profits a small part of family income & -0.039 & 0.009 \\
Sum of owner motivations & 0.889 & -0.056 \\
Motivated by lifestyle of producing cheese & 0.829 & -0.299 \\
Other non-financial motivations & 0.386 & -0.074 \\
Entertain other producers & 0.218 & -0.800 \\
Entertain consumers & 0.134 & -0.802 \\
Cover costs only & 0.175 & -0.099 \\
\hline
\end{tabular}

Table 3 - Factor Loadings 
Table 4 presents the correlations between the factors and owners' choice variables. Business is negatively related to the pleasure factor, and is insignificant. Business is also negatively related with price, positively significant with quality and insignificantly related to the use of traditional technology. Pleasure is positively related to price (insignificant), quality (5\% significance level) and technology (1\% significance level) as expected. In Figure 1, a scatter plot of business against pleasure supports the insignificant correlation between business and pleasure in Table 4.

\begin{tabular}{lccccc}
\hline & \multicolumn{5}{c}{ Factors and Choice Variables } \\
\hline & Business & Pleasure & Price & Quality & Technology \\
\cline { 2 - 6 } Pleasure & -0.068 & 1 & & & \\
Price & $-0.134^{* *}$ & 0.018 & 1 & & \\
Quality & $0.136^{* *}$ & $0.126^{* *}$ & -0.012 & 1 & \\
Technology & -0.009 & $0.283^{* * *}$ & 0.079 & -0.101 & 1 \\
\hline
\end{tabular}

Notes: $* * * 1 \% * * 5 \%$ and $* 10 \%$ significance levels.

Table 4 - Pair-wise Correlations; Factors and Owner Choice Variables

We now go on to test the three propositions of the theoretical model by estimating a system of equations using seemingly unrelated regressions incorporating our two new variables. 


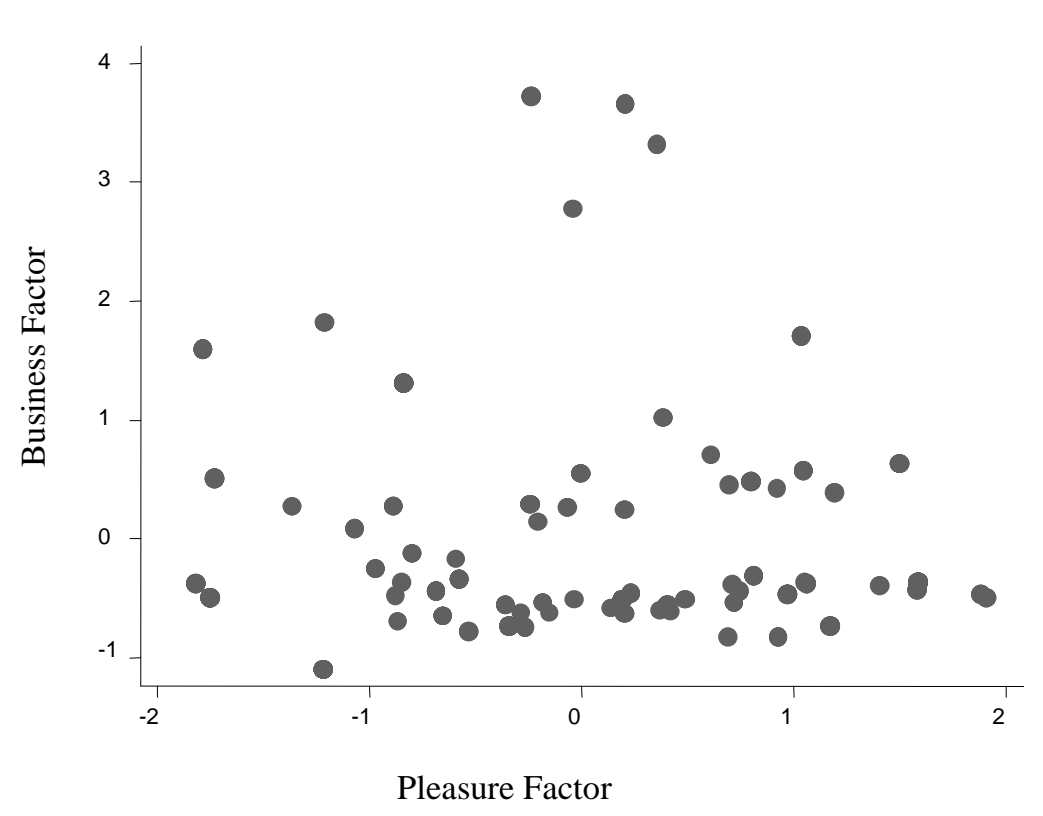

Figure 1 - Business vs. Pleasure 


\subsection{Seemingly Unrelated Regression}

In this section we present the empirical results. We now test the three propositions of the theoretical model. Our theory suggests a link between the choice of price, quality and use of an owner-specific production technology. Therefore, a seemingly unrelated regression (SUR) estimation is appropriate in this case. This is an econometric technique that accommodates any possible link within systems of equations. By estimating a linear system of three equations, it is possible to correlate the error terms across equations for a given cheese. It improves upon the efficiency of estimation compared to standard ordinary least squares (OLS) estimation. The general specification of a SUR model takes the following form, as described in Cameron and Trivedi (2005). In (5) the endogenous variable $y_{i g}$, is regressed using OLS on a vector of exogenous variables, $x_{i g}$ transposed, providing estimates of $\beta_{g}$.

$$
y_{i g}=x_{i g}^{\prime} \beta_{g}+\varepsilon_{i g} \quad g=1, \ldots, G \quad i=1, \ldots, I
$$

If we stack all $G$ equations for the $g^{\text {th }}$ producer we end up with (2.6) where $y_{i g}$ and $\varepsilon_{i g}$ are $G \times 1$ vectors, $x_{i g}$ is a $G \times K$ matrix and $\beta$ is a $K \times 1$ vector.

$$
\begin{aligned}
& {\left[\begin{array}{c}
y_{i g} \\
\vdots \\
y_{i G}
\end{array}\right]=\left[\begin{array}{ccc}
x_{i 1}^{\prime} & 0 & 0 \\
0 & \ddots & 0 \\
0 & 0 & x_{i G}^{\prime}
\end{array}\right]\left[\begin{array}{c}
\beta_{1} \\
\vdots \\
\beta_{G}
\end{array}\right]+\left[\begin{array}{c}
\varepsilon_{i 1} \\
\vdots \\
\varepsilon_{i G}
\end{array}\right]} \\
& {\left[\begin{array}{c}
\hat{\beta}_{1} \\
\vdots \\
\hat{\beta}_{G}
\end{array}\right]=\left[\begin{array}{c}
{\left[\sum_{i=1}^{P} x_{i} x_{i 1}^{\prime}\right]^{1} \sum_{i=1}^{\nu} x_{i 1} y_{i 1}} \\
{\left[\sum_{i=1}^{P} x_{i G} x_{i G}^{\prime}\right]^{1} \sum_{i=1} x_{i G} y_{i G}}
\end{array}\right]}
\end{aligned}
$$


In (7) it is shown that the seemingly unrelated OLS regression is in fact identical to that of OLS regression for each equation separately. However, as we suspect $a$ priori that errors are correlated, we use SUR estimation. We now go on to specify the formal model.

We specify three reduced form equations to test the three propositions of the theoretical model that employ the business and pleasure factors. The general model in (5) is adaptable to our data on cheeses stacked for all owners by simply letting $i$ now represent all cheeses across all owners.

In (8), (9) and (10) the endogenous variables are price $(P)$, quality $(S)$ and technology $(T)$ respectively. The exogenous variables are business $(B)$ and pleasure $(P L)$ in each equation. Note the negative sign on $B$ in (8), (9) and (10) reflecting our a priori expectation that owners with a higher business score will set lower profit maximising prices, produce a lower quality cheese and use nonowner-specific technology in production.

$$
\begin{aligned}
& P_{i 1}=\alpha_{11} P L-\alpha_{21} B+\varepsilon_{i 1} \\
& S_{i 2}=\alpha_{12} P L-\alpha_{22} B+\varepsilon_{i 2} \\
& T_{i 3}=\alpha_{13} P L-\alpha_{23} B+\varepsilon_{i 3}
\end{aligned}
$$




\begin{tabular}{|c|c|c|c|}
\hline Dependent Variable & Price & Quality $^{\text {a }}$ & Technology \\
\hline Pleasure & $0.322 \quad(1.309)$ & $0.243 * * \quad(0.165)$ & $0.107 * * *$ \\
\hline Business & $-3.215^{* * *}(1.408)$ & $0.578 * * *(0.077)$ & $(0.020)$ \\
\hline Constant & $11.167 * * *(1.218)$ & $3.580 * * * \quad(0.153)$ & $0.847 * * * \quad(0.021)$ \\
\hline Observations & 285 & 285 & 285 \\
\hline Chi-square & 5.310 & 12.610 & 23.300 \\
\hline p-value & 0.070 & 0.002 & 0.000 \\
\hline
\end{tabular}

Notes: Standard errors in parentheses. $* * * 1 \%$ significance, $* * 5 \%$ significance, and $* 10 \%$ significance.

${ }^{a}$ Quality is measured in terms of the \% of milk used in production from the owner's own herd or flock.

Table 5 - Reduced Form SUR Estimation

\begin{tabular}{lcll}
\hline & Price & Quality $^{\mathbf{a}}$ & Technology \\
\hline Price & 1.000 & & \\
Quality & -0.012 & 1.000 & 1.000 \\
Technology & 0.079 & $-0.145^{* *}$ & 1.00 \\
\hline
\end{tabular}

Notes: $* * * 1 \%$ significance, $* * 5 \%$ significance, and $* 10 \%$ significance. ${ }^{\text {a }}$ Quality is measured in terms of the $\%$ of milk used in production from the owner's own herd or flock.

Table 6 - Pair-wise Correlations; SUR Error Terms 
Table 5 presents the results of the SUR estimation. Our theoretical model is set up in such a way that owners are assumed to have a parameter of importance, $\beta$, on nonprofit utility. However, the methodology in which we have attempted to separate owners based on their motivation allows for a range of motivations to be accounted for in the SUR estimation. To clarify, owners can potentially possess one of four different types of motivation: (1) a high pleasure score and a high business score, (2) a high pleasure score and a low business score, (3) a low pleasure score and a high business score and (4) a low pleasure score and a low business score. This because we have estimated a business and pleasure score for each owner.

The business score adds a new dimension to owner motivation assumed in the theoretical model. Instead of owners just having some value of $\beta$, they also have parameter of importance for profit, $\alpha$, suggesting a two-dimensional relationship exists for owner motivation, where the above four motivation types are located. Figure 1 suggests that there are owners with a high pleasure score in the high $\beta$ (pleasure), low $\alpha$ (business) quadrant. Therefore, there are owners motivated by utility beyond purely profits. However, there are also owners that appear to be motivated by profit in the low $\beta$ and high $\alpha$ quadrant. There also appear to be owners that are utility motivated and profit motivated in the high $\beta$ and low $\alpha$ quadrant. These producers may be small-scale and entrepreneurial. This range of motivation influences the interpretation of the SUR estimation in Table 5.

Taking price first, there is evidence to suggest that owners with higher business scores set lower profit maximising prices, whilst owners with higher pleasure scores insignificantly set higher prices. This provides some support for proposition three of the theoretical model. The estimation suggests that owners with a higher business score, regardless of the fact that they may have a high or low pleasure score, given that the coefficient on pleasure is insignificant, will set lower prices.

The second estimation in Table 5 suggests that a range of motivations may be influencing the quality of cheese produced by owners. Both coefficients on business and pleasure are positive and significant, supporting proposition two, to some extent. However, the results also suggest evidence that three types of owner motivation may 
be present, influencing the quality level set by owners. We have already inferred that owners with a high pleasure score and a high business score produce a higher quality cheese, but it may also be the case that owners with a high pleasure score and low business score or a low pleasure score and a high business score may well also produce a higher quality cheese compared to other types of owner motivation. The sizable difference in magnitude of the coefficient on business compared to pleasure could suggest that owners with a high business score set a higher degree of quality. In this case they use a higher percentage of milk from their own herd or flock in production. It may also be the case that owners with higher business scores realise that quality is important to consumers.

An explanation for this relationship could be related to our measure of quality. Enterprises that use a high percentage of milk that is from their own herd or flock could be small, but could also be large in size. Larger enterprises employing higher proportions of milk from their own herds or flocks are more likely to have higher business scores than those for pleasure. Therefore it is likely that scale economies exist in herd size. At the end of our discussion of the results presented in Table 5, we shall discuss the use of an alternative measure of cheese quality.

The third set of results in Table 5 suggests that owners with higher pleasure scores use traditional production technologies. This supports proposition one. The result suggests that owners that use a traditional production technology are those with high pleasure scores and low business scores, given owners with higher business scores are insignificantly related to the use of a traditional production technology. This may be suggesting that owners that employ traditional production methods are those that are heavily motivated by the pleasure of doing so and that business motivations are unimportant.

We began this section by briefly stating that we expect to observe some evidence that an owner's decision-making with regard to price, quality and the use of a traditional production technology is related. Therefore, we would expect to observe positive correlations between the error terms of the three equations specified in the SUR estimation. The correlations between equations (8), (9), and (10) are presented in Table 6. Only the errors of the equations representing an owner's choice of using an 
owner specific production method and level of cheese quality are positively related and significant at the 5\% level. The other error terms are positively related, but are not significant. Therefore we do not have conclusive evidence that the three decisions of the owner are related in all cases.

We now turn to discuss the results when using a different measure of cheese quality. In appendix $\mathrm{B}$ we present the same estimation as in Table 5, but with cheese production time as a measure for cheese quality. This measure was also verified by an expert. Younger cheeses are said to be of a lower quality, with some exceptions for softer cheeses such as goat's cheese. Older cheeses inherit more flavour and texture from their maturity.

The results presented in Table B.1 are contrary to those presented in Table 5. Higher pleasure scores are related to higher prices at the 5\% significance level. Owners with higher business scores set lower profit maximising prices, but this is insignificant. This suggests that regardless of their business score, owners with higher pleasure scores set higher prices, given the insignificant coefficient on the business factor. Higher pleasure scores are related to higher quality at the $10 \%$ significance level. In comparison, higher business scores are now related to a lower quality, but this is insignificant. Therefore, this suggests that just owners with a combination of high pleasure scores, regardless of their business score, produce higher quality cheese. Higher pleasure scores are negatively related to the use of a traditional production technology, whereas higher business scores are positively related, both at the $1 \%$ significance level. This may be due to owners with higher business scores using traditional production methods as a way of differentiating their products. However, it also suggests that owners that are using traditional production methods are those with high business scores and low pleasure scores.

The use of production time as a measure of cheese quality suggests some alternative results to those when using the first measure of cheese quality. We now have support for propositions two and three of the theoretical model, but not for proposition one. We present these findings for comparison in appendix B because the SUR estimation was of a lesser goodness of fit compared to the SUR estimation in Table 5. 
In this section we first conducted principal factor analysis to our data on owner motivations in order for us to investigate the propositions of the theoretical model, using a seemingly unrelated regressions model. Using the proportion of milk used by the owner originating from their own herd or flock, we found some evidence in support of propositions one and two, but with reservations. Proposition three is more clear cut. Using a second measure for cheese quality, we find contradictory evidence to suggest support for propositions two and three but not proposition one. In the next section we summarise the paper and discuss some implications of these findings.

\subsection{Summary}

This paper investigated empirically whether owner motivations within the UK speciality cheese sector were consistent with neoclassical models of profit maximisation. Supply decisions (i.e. pleasure from production) are shown to be more important to some owners, other than just the standard neoclassical assumption for the demand-side (i.e. ability to generate revenues) of profit maximisation. In this paper we find evidence to suggest that this is the case for the UK speciality cheese sector.

Information was gathered on owner motivation from the UK speciality cheese sector to test empirically a theoretical model that allows owners to consider not only profit, but also utility, in their choices of price, product quality and the use of a traditional production technology.

We find evidence of systematic utility maximisation in the UK speciality cheese sector. Our empirical estimations suggest that a range of motivation types exist across owners within this sector. Empirical estimations support two of the propositions of the theoretical model. Utility maximising owners do use traditional production technologies. However, contrary to this finding, profit maximising owners were also shown to use such methods. Utility maximising owners were also found to produce higher quality cheese. Lastly, utility maximising owners set higher profit maximising prices, but surprisingly this was statistically insignificant. 
These findings are consistent to some extent with those of Scott Morton and Podolny (2002). The findings of this paper have implications for the UK speciality cheese sector, in general. First, objective function heterogeneity does influence the internal policy of enterprises when making decisions on which product characteristics to supply to the market. Therefore, contrary to traditional neoclassical models, owners can influence the product characteristics supplied to the market through pleasure in production. Second, those owners that demonstrate utility maximising behaviour towards their product may well, as a result, increase the supply, thus benefiting producers as well as consumers. Third, owner objective function heterogeneity, in the utility maximising sense, will influence entry behaviour when profit maximising owners enter with cost efficiencies. Instead of not entering the sector, utility maximising owners will enter even when they have more profitable motivations as they aim to maximise utility beyond profit. 


\section{References}

Cameron, A. C. \& Trivedi, P.K., (2005), Microeconometrics. Methods and Applications, Cambridge (New York).

Christy, R. \& Norris, G., (1999), Discovery Markets: Communicating Product Identities in Specialised Sectors, British Food Journal, Vol. 101, No. 10, pp. 797-808.

De Roost, K. \& Menghi, A., (2000), Reconsidering 'Traditional' Food: the Case of Parmigiano Reggiano Cheese, Sociologia Ruralis, Vol. 40. No. 4, pp. 439-451.

Dillman, D. A. (1978), Mail and Telephone Surveys: The Total Design Method, Wiley \& Sons INC (New York), $1^{\text {st }}$ Edition.

DTZ Pieda Consulting (1999), UK Speciality Food and Drink Sector, 1999 (October), Edinburgh.

Freeman, S., (1998), The Real Cheese Companion. A Guide to Best Handmade Cheeses of Britain and Ireland, Time Warner (London).

Jones, P., Comfort, D. \& Hillier, D., 2004, A case study of local food and its routes to market in the UK, British Food Journal, Vol. 106, No. 4, pg. 328-335.

Kupiec, B. \& Revell, B., (1998), Speciality and artisanal cheeses today: the product and the consumer, British Food Journal, Vol. 100, No. 5, pp. 236-243.

Scott Morton, F. M. \& Podolny, J. M., (2002), Love of Money? The Effects of Owner Motivation in the California Wine Industry, Journal of Industrial Economics, Vol. 50, No. 4, pp. 431-456.

Tregear, A., (2003a), Market orientation and the craftsperson, European Journal of Marketing, Vol. 37, No. 11/12, pp. 1621-1635.

Tregear, A., (2003b), From Stilton to Vimto: Using Food History to Re-think Typical Products in Rural Development, Sociologia Ruralis, Vol. 43, No. 2, pp 91-107. 


\section{Appendix A Sufficient Second-Order Conditions and Outline Proofs of Theoretical Propositions}

The formal propositions presented in Section 2 are subject to the second-order conditions for (1) being met. Sufficient second-order conditions and second-order cross partials are helpful in signing the comparative static results.

We first restate the maximisation problem and the relevant assumptions made in Section 3:

$\max _{p, s, t} u(p, s, t)$ where $u(p, s, t)=q(p, s) p-C(q(p, s), s, t)+\beta \lambda(s, t)$

The standard economic assumptions justified in the text are:

$q_{p}<0, q_{p p}<0, q_{s}>0, q_{p s}>0, q_{s s}<0, C_{q}>0, C_{q q}>0, C_{s}>0$,
$C_{s t} \approx 0 C_{s s}>0, C_{q s}>0, C_{t}>0, C_{t t}>0, C_{q t} \geq 0, \lambda_{s}>0, \lambda_{s s}<0$,
$\lambda_{t}>0, \lambda_{t t}<0, \lambda_{s t} \approx 0$.

The first-order conditions are as follows:

$$
\begin{aligned}
& u_{p}=p q_{p}(p, s)+q(p, s)-C_{q}(q(p, s), s, t) q_{p}(p, s)=0 \\
& u_{s}=p q_{s}(p, s)-C_{q}(q(p, s), s, t) q_{s}(p, s)-C_{s}(q(p, s), s, t)+\beta \lambda_{s}(s, t)=0 \\
& u_{t}=-C_{t}(q(p, s) s, t)+\beta \lambda_{t}(s, t)=0
\end{aligned}
$$

From (A.2), price must exceed marginal cost at all strictly positive outputs:

$$
\left(p-C_{q}\right)>0
$$

To satisfy that $u(p, s, t)$ is a well-defined maximisation problem, the Hessian matrix and the relevant principal minors must alternate in sign as follows: $\left|H_{1}\right|<0,\left|H_{2}\right|>0$ and $|H|<0$.

$\left|H_{1}\right|<0$

requires $u_{p p}<0$.

$\left|H_{2}\right|>0$

requires $\left(u_{p p} u_{s s}-u_{s p} u_{p s}\right)>0$ 
$\left|H_{3}\right|=|H|=\left|\begin{array}{lll}u_{p p} & u_{p s} & u_{p t} \\ u_{s p} & u_{s s} & u_{s t} \\ u_{t p} & u_{t s} & u_{t t}\end{array}\right|<0$

Solving $|H|$ provides (A. 11)

$-u_{p s}\left(u_{s p} u_{t t}-u_{t p} u_{s t}\right)+u_{s s}\left(u_{p p} u_{t t}-u_{t p} u_{p t}\right)-u_{t s}\left(u_{p p} u_{s t}-u_{s p} u_{p t}\right)<0$

Sufficient for (A.11):

$$
\begin{aligned}
& \left(u_{p p} u_{s t}-u_{s p} u_{p t}\right)<0 \\
& \left(u_{p p} u_{t t}-u_{t p} u_{p t}\right)>0 \\
& \left(u_{s p} u_{t t}-u_{t p} u_{s t}\right)>0
\end{aligned}
$$

To ensure negative definiteness of the Hessian matrix we proceed to sign the secondorder conditions and the second-order cross partials. From (A.0), (A.1) and (A.5) it is straightforward to sign the following:

$$
\begin{aligned}
& u_{p p}=\left(p-C_{q}\right) q_{p p}+2 q_{p}-C_{q q}\left(q_{p}\right)^{2}<0 \\
& u_{p s}=u_{s p}=\left(p-C_{q}\right) q_{p s}+q_{s}-C_{q q} q_{s} q_{p}-C_{q s} q_{p}>0 \\
& u_{p t}=u_{t p}=-C_{q t} q_{p}>0 \\
& u_{s s}=\left(p-C_{q}\right) q_{s s}-C_{q q} q_{p}^{2}-2 C_{q s} q_{s}-C_{s s}+\beta \lambda_{s s}<0 \\
& u_{t t}=C_{t t}+\beta \lambda_{t t}<0 \\
& u_{s t}=u_{s t}=-C_{q t} q_{s}-C_{s t}+\beta \lambda_{s t}
\end{aligned}
$$

Given (A.1), $u_{s t} \leq 0$ for low $\beta$. We would expect $u_{s t}=u_{t s} \approx 0$ as the production method is assumed not to influence the quality of the product $\left(\lambda_{s t} \approx 0\right)$. 
We now go on to prove the propositions outlined in Section 2.2. In matrix notation, the comparative statics of raising $\beta$ (i.e. putting more weight on non-profit factors):

$$
\left[\begin{array}{lll}
u_{p p} & u_{p s} & u_{p t} \\
u_{s p} & u_{s s} & u_{s t} \\
u_{t p} & u_{t s} & u_{t t}
\end{array}\right]\left[\begin{array}{c}
d p \\
d s \\
d t
\end{array}\right]=\left[\begin{array}{c}
0 \\
-\lambda_{s} d \beta \\
-\lambda_{t} d \beta
\end{array}\right]
$$

Using Cramers' Rule we can solve for $d p / d \beta, d s / d \beta$ and $d t / d \beta$. These can be signed using (A.13-18) and the second-order conditions.

Proposition One: Utility maximising owners are more likely to use owner-specific production methods.

\section{Proof:}

$$
\frac{\partial t}{\partial \beta}=\frac{\left|\begin{array}{ccc}
u_{p p} & u_{p s} & 0 \\
u_{s p} & u_{s s} & -\lambda_{s} \\
u_{t p} & u_{t s} & -\lambda_{t}
\end{array}\right|}{|H|}
$$

Since $|H|<0$, we require the numerator of (A.21) to be negative:

$$
\lambda_{s}\left(u_{p p} u_{t s}-u_{t p} u_{p s}\right)-\lambda_{t}\left(u_{p p} u_{s s}-u_{s p} u_{p s}\right)<0
$$

This follows from (A.1), (A.9) and (A.12).

Proposition Two: If quality is more important than the use of an owner-specific production method, such that $\lambda_{s}$ is sufficiently greater than $\lambda_{t}$, then utility maximising owners will produce a higher quality product.

\section{Proof:}

$$
\frac{\partial s}{\partial \beta}=\frac{\left|\begin{array}{ccc}
u_{p p} & 0 & u_{p t} \\
u_{s p} & -\lambda_{s} & u_{s t} \\
u_{t p} & -\lambda_{t} & u_{t t}
\end{array}\right|}{|H|}
$$

Since $|H|<0$, we require the numerator in (A.23) to be negative:

$$
-\lambda_{s}\left(u_{p p} u_{t t}-u_{t p} u_{p t}\right)+\lambda_{t}\left(u_{p p} u_{s t}-u_{s p} u_{p t}\right)<0
$$

This follows from (A.1) and (A.12). 
Proposition Three: Utility maximising owners will set higher prices.

Proof:

$\frac{\partial p}{\partial \beta}=\frac{\left|\begin{array}{ccc}0 & u_{p s} & u_{p t} \\ -\lambda_{s} & u_{s s} & u_{s t} \\ -\lambda_{t} & u_{t s} & u_{t t}\end{array}\right|}{|H|}$

Since $|H|<0$, we require the numerator in (A.25) to be negative:

$\lambda_{s}\left(u_{p s} u_{t t}-u_{p t} u_{t s}\right)-\lambda_{t}\left(u_{p s} u_{s t}-u_{s s} u_{p t}\right)<0$.

This follows from (A.1) and (A.13 - A.18). 


\begin{tabular}{|c|c|c|c|c|c|c|}
\hline \multirow{2}{*}{$\begin{array}{l}\text { Dependent Variable: } \\
\text { Pleasure }\end{array}$} & \multicolumn{2}{|c|}{ Price } & \multicolumn{2}{|c|}{ Quality $^{\mathbf{a}}$} & \multicolumn{2}{|c|}{ Technology } \\
\hline & $2.438 * *$ & $(1.212)$ & $8.644 *$ & (5.703) & $-0.084 * * *$ & $(0.000)$ \\
\hline Business & -0.611 & (1.206) & 0.670 & $(5.675)$ & $0.072 * * *$ & $(0.000)$ \\
\hline Constant & \multicolumn{2}{|c|}{$11.042 * * *(1.231)$} & $87.913^{*}$ & $*(5.791)$ & $0.842 * * *$ & $(0.000)$ \\
\hline Observations & \multicolumn{2}{|c|}{288} & \multicolumn{2}{|c|}{288} & \multicolumn{2}{|l|}{288} \\
\hline Chi-square & \multicolumn{2}{|c|}{4.330} & \multicolumn{2}{|c|}{2.310} & \multicolumn{2}{|l|}{30.590} \\
\hline p-value & \multicolumn{2}{|c|}{0.1150} & \multicolumn{2}{|c|}{0.315} & \multicolumn{2}{|l|}{0.000} \\
\hline
\end{tabular}

Notes: Standard errors in parentheses. $* * * 1 \%$ significance, $* * 5 \%$ significance, and $* 10 \%$ significance. ${ }^{a}$ Quality is measured as the time to produce.

Table B.1 - Reduced Form SUR Estimation; Production Time as Measure of Quality

\begin{tabular}{lccl}
\hline & Price & Quality $^{\mathbf{a}}$ & Technology \\
\hline Price & 1.000 & & \\
Quality & -0.041 & 1.000 & \\
Technology & $0.119^{* *}$ & -0.041 & 1.000 \\
\hline
\end{tabular}

Notes: $* * * 1 \%$ significance, $* * 5 \%$ significance, and $* 10 \%$ significance. ${ }^{\text {a }}$ Quality is measured as the time to produce.

Table B.2 - Pair-wise Correlations; Errors for All Three Equations 